weigh refuse ashes, clinkers and coal, for deduction. In this oase, tho evaporative capacity of the boiler should be estimated from the time the fire is bright, but for the economy, the total water evaporated from the commencement is to be divided by the total weight of com. bostible used minus the refuse.

The trial, if accuracy is desired, should not be less than of ten hours' duration. A longer trial would reduce the uncertainties to a smaller proportion.

Philadelphia, Oct. 15, 1873.

EdWd. BRown, JOHN H. COOPER, ROBT. Briggs.

\title{
ON A NEW HYDRAULIC RAILROAD CAR BRAKE,
}

By William M. Hzandrason, Philadelphia.

A paper read before the Franklin Institute Oct. 15, 1873.

The principle involved in the operation of this brake is that of hydraulic pressure, and the motive power is derived directly from the steam-boiler of the locomotive, and under the control of the engineer.

There is first a three-branch or two-way cock placed underneath the foot-plate of the engine, its plug actuated by a stem carried up through the foot-plate, and furnished with a horizontal lever at top, carrying an index pointer, traversing a quadrant plate marked on and off, with gradation marks between, as a guide to the engineer in operating the brakes; and there is also a small pressure gauge, placed conveniently before him, to show him the pressure he is applying. The nozzle of the cock, marked 1 , is connected by a short piece of wrought iron pipe directly to the water space of the boiler; the opposite nozzle, marked 2, is connected by wrought iron pipe and flexible hose connections, furnished with valvular couplings between the cars, as usual in such cases, and leads directly to pressure boxes placed between the brake beams of each truck; the third nozzle, marked 3, is connected directly to the water tank supplying the boiler with water.

The construction of the pressure boxes is as follows: A cylindrical vessel of cast iron is furnished, having flunges at either end; it is about 9 inches in diameter and 3 inches deep, the inner diameter being about 5 inches. Two tlexible dishnshaped diaphragms are next introduced, back to back, having about half an inch space between them, and are secured in position by rings bolted firmly to the drum, 
making an air-tight joint. Into the interior of the dish-shaped diaphragm are fitted two rams, working in opposite directions; these are bolted by rectangular flanges to the centre of the brake beans, carrying the brake shoes. Guide rods are also provided to support the drum in position relative to the rams; these are simply two pieces of $\frac{3}{4}$ round iron, passing through lugs cast on the two sides of the drum and through the flanges of the rams.

The operation of this apparatus is as follows: Steam being up in the boiler, and the connections of the main pipe being all coupled between the several cars, the engineer will turn the plug of the twoway cock so as to establish a communicution between the water tank and the main, as shown by fig. 4 . He then passes to the rear end of the train, and opens a small air-cock placed at the extremity of the main, and allows the water to travel to that point. This it will do by virtue of the head of water contained in the tank. When the air is expelled the engineer will close the cock, return to the engine, and is then prepared to start. We will now suppose the train in motion, and it is desired to apply the brakes. The engineer will simply turn the plug of the two-way cock so as to make a communication between the boiler and the main, as shown by fig. 5 . It will be observed, in doing this, he will have shut off all communication with the water tank. Now, then, the pressure within the boiler will exert itself upon the water column, and produce a bydro-dynamic pressure equal to the boiler pressure upon each square inch presented by the area of the rams, when turned on full head; or the pressure to be applied can be varied by partially opening the eock; or a special provision can be made in the shape of the valve openings, so as to produce such graduated result. Taking the usual pressure carried on our locomotive boilers, $120 \mathrm{lbs}$. per square inch, and applying this pressure to our 5 -inch rams, we have above $2800 \mathrm{lbs}$. of force brought to

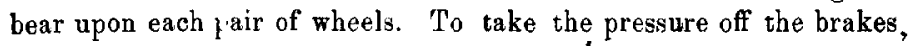
the plug of the two-way cock is turned back to its original position, opening a communication again with the water tank, as shown by fig. 4. This shuts off all communication with the boiler, and of course destroys the hydraulic pressure. The diaphragms being thus relieved will recover their normal, condition by reason of their own elasticity, and the beams carrying the brake shoes will be thrown off the wheels by the springs invariably provided for that purpose. The surplus water will then be discharged into the water tank, preventing any waste either of water or heat, becoming a part of the feed-water to 


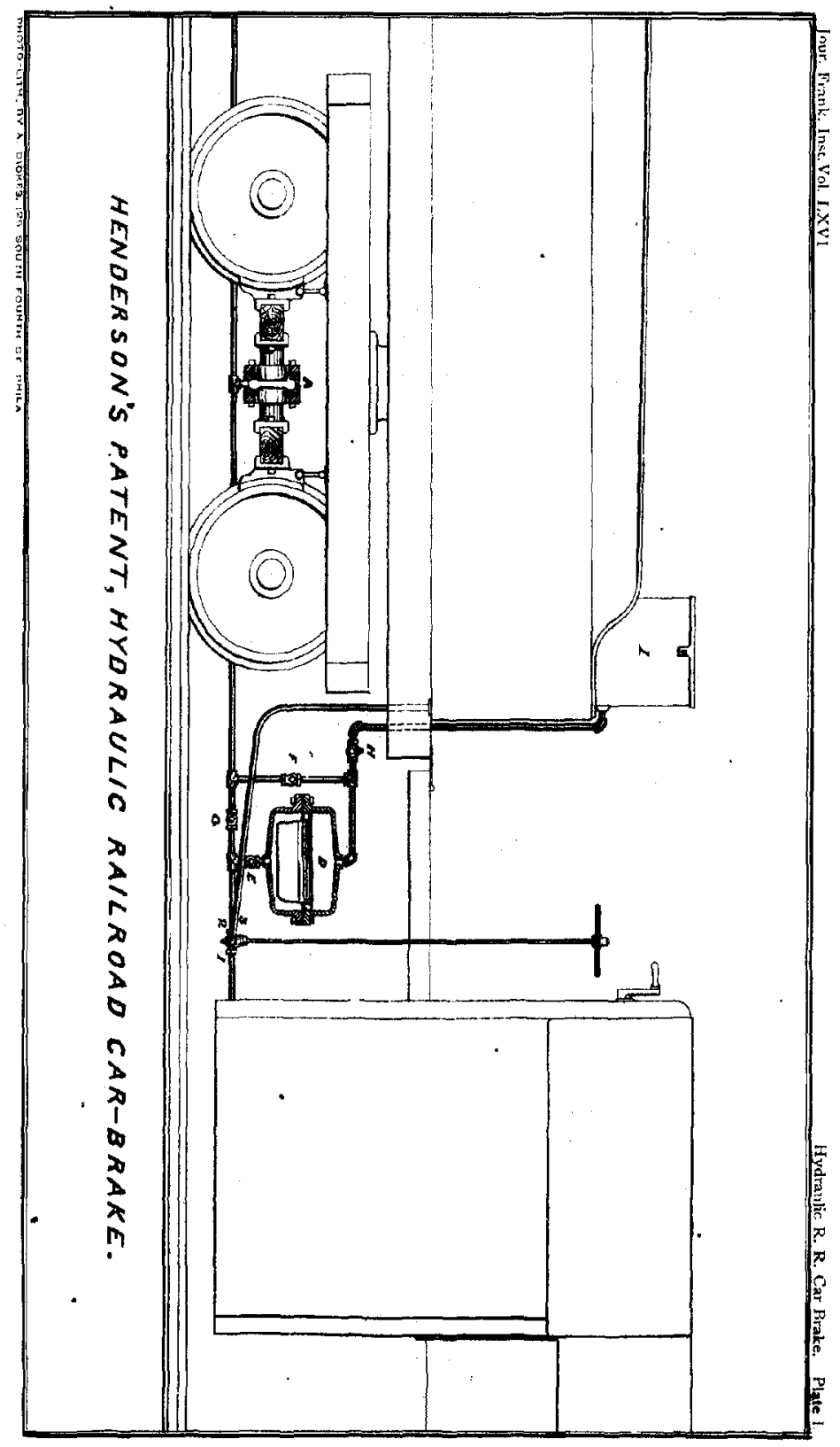


be returned to the boiler. There are stops obviously arranged between the body of the two-way cock and its plug, in such manner that the plug can never be turned so as to open a communication between the steam-boiler and the water tank. In order that the force of applying the brakes shall not be of an objectionable concussive or jarring nature, two means have been provided: first, an air-vessel placed on top of the pressure boxes, which will furnish a cushion of air to absorb it; and, second, springs of rubber or other elastic material placed between the brake beams and the shoes to relieve it.

The above-described apparatus is all that will be required to efficiently equip a train of cars south of Mason and Dixon's line, and will be equally efficacious for about nine months in the year in the Northern States. To adapt this invention for low temperatures, the following device is made attachable:

A cast iron cylindrical ressel is provided, of a capacity to contain sufficient non-freezing fluid to charge the maximum number of pressure boxes usually employed on a train of cars. It is made in halves, and embraces at the joint, where it is bolted together, the flange of a donble corrugated flexible diaphragm, making an air-tight joint. The fluid to be used for operating the brake pressure boxes is placed above the diaphragm, and the pressure from the boiler is applied below. As the pressure on either side will be the same during its operation, the medium is therefore a mere separator, preventing the fluids on either side of it from commingling. For the non-freezing fluid, glycerin and water in equal parts is preferred, which is safe to about $30^{\circ}$ below zero. (Glycerin itself never freezes). The glycerin chauber is connected to the main $r$ a short tubular connection, furnished with a stop-cock, E. Leading away from the other end of this chamber is another tube connection, making an advanced connection with the main, and is also furnished with a stop-cock, F. Between the point of junction of these two connections there is placed another stopcock, $G$. When the cocks $\mathrm{E}$ and $\mathrm{F}$ are shut and $\mathrm{G}$ opened, the brakes will be operated entirely by water from the tender tank. When the cocks $E$ and $F$ are opened and $G$ is shut, whatever fluid is used to operate the brakes must come solely from the glycerin chamber. The pressure from the boiler, acting upon the underneath side of the diar phragm, will cause a discharge of the fluid to operate the diaphragm of the pressure boxes, as before; and when the brakes are let off this fluid will return to the glycerin chamber, the diaphragm making room for it by adjosting itself to its normal state, and the water under 
pressure will be delivered into the tender tank precisely as previonsly described. In order that the glycerin ehamber shall remain at all times fully charged with fluid, a tank or reservoir is provided on the tender, containing an excess quantity. The pipe proceeding from this tank to the glycerin chamber has a check-valve fitted to it, opening towards the glycerin chamber, so that this result must be fully accomplished; for, if a vacuity should occur in the glyoerin chamber from loss by aceidental leakage, the loss will be immediately made good from the reservoir, while a disposition for any of the fluid to return is instantly checked by the closing of the check-valve.

This brake can be applied equally well to the outside of the wheels, and is adapted to any kind of truck, either four or six. wheeled.

As compared to other brakes, the saving effected consists in doing away with the stearn-pump and receiver, all cylinders, pistons, stuffing-boxes, lever-rods and springs, all packing, lubricating, and a total exclusion of dust.

\section{BELTING FACTS AND FIGURES.}

By J. H. CoOprr.

(Continued from page 329.)

The following notes on belting are taken from Mr. B. F. Sturtevant's illustrated catalogue of Pressure Blowers, Boston, Mass. :

"Double Belts are calculated to be one-third of an inch thick, single belts one-fifth of an inch thick. The holding power of the belt is governed wholly by its tension or tightness and the condition of its surface, the diameter of the pulleys having nothing to do with it, and is capable of being increased by tightening to 350 pounds to 1 square inch of cross section.

: "As a general rule, belts running from a large to a small pulley, slip on the large and not on the small one, as is commonly supposed. This is explained as follows: The pressure per square inch with which the belt hugs the small pulley is just as much greater as the small pulley is less in diameter thin the large one, and the friction of the belt more than follows the increased pressure. For example: If you cover the small pulley on the counter with leather, to prevent slipping, you must also cover the driving pulley on the main line, or you get no benofit from covering the small pulley. These remarks apply to horizontal belts.

"A table is given for finding the width in inehes of double main 